\section{$\underset{\substack{\text { hommes } \\ \text { \& migrations }}}{ }$}

\section{Hommes \& migrations}

Revue française de référence sur les dynamiques

migratoires

$1280 \mid 2009$

Les Turcs en France : quels ancrages?

\title{
Turquie, France : le voyage des mots
}

\section{Georges Bertrand}

\section{CpenEdition \\ Journals}

\section{Édition électronique}

URL : http://journals.openedition.org/hommesmigrations/313

DOI : 10.4000/hommesmigrations.313

ISSN : 2262-3353

\section{Éditeur}

Musée national de l'histoire de l'immigration

Édition imprimée

Date de publication : 1 juillet 2009

Pagination : 100-104

ISSN : 1142-852X

Référence électronique

Georges Bertrand, «Turquie, France : le voyage des mots », Hommes \& migrations [En ligne], 1280 |

2009, mis en ligne le 29 mai 2013, consulté le 14 novembre 2019. URL : http://

journals.openedition.org/hommesmigrations/313; DOI : 10.4000/hommesmigrations.313 


\section{Turquie, France : le voyage des mots}

Par Georges Bertrand ${ }^{(1)}$, linguiste

De "sofa" à "kefta", de nombreux mots, issus ou passant par le monde turc, sont entrés dans la langue française. Petite histoire des emprunts lexicaux au carrefour des imaginaires en provenance de l'Orient. 
Le français s'est enrichi tout au long de son histoire d'un vocabulaire venu d'Orient et, en particulier, des terres qui firent partie, dès les VII ${ }^{e}$ et VIII ${ }^{e}$ siècles de l'ère chrétienne, des différents empires musulmans qui s'étendirent, plus ou moins, du Maghreb à l'ouest de la Chine, englobant ainsi aussi bien le monde arabe que le perse ou le turc. Au cours du Moyen-Âge, il s'était plutôt agi d'emprunts à la langue arabe, qui elle-même s'était abreuvée aux sources grecque, perse, sanscrite et même extrême-asiatique. Et la civilisation en devenir qui s'établissait peu à peu en Europe occidentale serait redevable à maints égards envers celle qui avait fleuri, avant elle, en Méditerranée.

À partir du XVI ${ }^{\mathrm{e}}$ siècle, c'est plutôt un vocabulaire issu du monde turc qui commence à enrichir la langue française en raison des relations qui s'établirent entre le royaume de France et l'Empire ottoman. Ces liens furent tout d'abord d'ordre militaire : le roi François I ${ }^{\mathrm{er}}$ est capturé

Pendant plusieurs siècles
d'ailleurs, les équipées
corsaires, qu'elles furent
musulmanes ou chrétiennes
nourriront une abondante
littérature où les fantasmes
s'allieront aisément
aux relations de batailles
ou aux souvenirs d'anciens
esclaves.
en 1525 par les Habsbourg, dynastie germanique alors dirigée par Charles Quint, et la France demande l'aide de Soliman, le sultan ottoman qui deviendra dans notre imaginaire "Soliman le Magnifique". Ce dernier répond favorablement, attaquant l'Empire germanique par l'est, envahissant la terre des Magyars, lui donnant au passage son nom actuel en Occident de "Hongrie", assiégeant Vienne aujourd'hui capitale de l'Autriche, ainsi que Nice dans le sud de la France qui était aux mains des Espagnols, eux-mêmes placés sous l'autorité de l'empereur germanique. Ce siège ottoman fut coordonné depuis Marseille par un corsaire qui devint fameux, Khizr, frère d'un certain Aroudj, corsaire lui aussi et tué à Tlemcen, en terre berbère, en 1518. Khizr, devenu capitaine de la flotte turque, se fit appeler Khayr ed-Din, "le bien de la religion", et prit le surnom de Baba Aroudj, transformé en Occident en Barberousse, peut-être en raison de la couleur de sa barbe, mais surtout parce qu'il était établi en Berbérie, la terre des Barbares de l'ancien Empire romain. Les corsaires venus du nord de l'Afrique devinrent des Barbaresques, le suffixe ajoutant au... pittoresque.

Pendant plusieurs siècles d'ailleurs, les équipées corsaires, qu'elles fussent musulmanes ou chrétiennes, nourriront une abondante littérature où les fantasmes s'allieront aisément aux relations de batailles ou aux souvenirs d'anciens esclaves. Rabelais, lui, mettra en scène des Turcs cannibales dans Gargantua, les Mousaffizs, substantif signifiant, mais en arabe "embrocheur", et le nom "sultan" deviendra peu à peu (et ce n'est pas un hasard) un nom propre pour désigner un chien... 


\section{L'Orient ou l'imaginaire du désir}

En 1535, la France installe sa première ambassade à Istanbul. Et en 1544, ce sera Barberousse lui-même qui accueillera à bord de son navire le nouvel ambassadeur de France pour le conduire à Istanbul prendre ses fonctions. Le sultan accorde sur son territoire des "privilèges" à la France dans trois domaines : juridique, commercial, et surtout culturel et cultuel. Les catholiques français présents sur le territoire ottoman, et surnommés "Levantins", peuvent ainsi exercer leur religion, commercer librement et parler leur langue. Un ambassadeur de France ira même jusqu'à déclarer que les "Français vivent en Turquie comme s'ils étaient au milieu de la France". Du fait de cette alliance, l'économie des deux royaumes est prospère : Istanbul attire les marchands européens et une ville comme Marseille s'enrichit et se développe considérablement grâce au commerce avec l'Empire ottoman.

Alors que les apports arabes des siècles précédents furent principalement liés au développement de savoirs (mathématique, botanique, construction navale, etc.), les apports turcs vont être placés sous le signe de l'exotisme, du "désir d'Orient". Un Orient qui, par le vocabulaire emprunté, confirmera les fantasmes nourris par l'Occident, et donc par la France, sur ce monde, proche, mais semblant ô combien lointain.

Malgré quelques réticences, l'attraction sera générale et on aimera dans certains milieux aristocratiques s'asseoir au choix sur un divan (mot à la longue et sinueuse histoire) ou sur un sofa pour déguster à l'aise un café (pas nécessairement turc d'ailleurs, même si c'est à l'ambassadeur de Turquie en France que l'on doit l'arrivée du premier pied de café à Versailles, offert fort opportunément au roi Louis XIV en 1669), les pieds posés sur des kilims que l'on foulera de délicates babouches... Même si ces mots sont eux-mêmes souvent empruntés soit au persan soit à l'arabe, c'est grâce à l'intermédiaire du turc qu'ils pénètrent en France. On rêve d'une existence de pacha, coiffé d'un turban, et entouré d'odalisques assises au milieu d'une somptueuse chambre décorées de tulipes... Les fantasmes d'ordre érotique ne sont en effet pas absents, des eunuques du harem aux intrigues d'un sérail qui n'est pas encore de Galata...

Sous Henri IV, Louis XIII et Louis XIV, les contacts se sont renforcés, donnant naissance à une mode dans les milieux aisés, aristocrates ou bourgeois : les "turqueries". Molière, dans son Bourgeois Gentilhomme, met en scène un grand Mamamouchi, invention lexicale pour désigner un pseudo-haut dignitaire turc à partir de l'arabe mamnuh chay, littéralement "chose interdite", puis "propre à rien", ainsi qu'un ballet turc avec derviches et muftis. Racine, avec sa tragédie Bazajet, inspirée d'un fait réel, relate le destin tragique d'un prince qui devra assumer son destin de demi-frère d'un sultan de la Sublime Porte. 


\section{Quand l'Empire ottoman noumissait les arts}

La mode s'étend à l'Europe entière et on crée partout des "turqueries", aussi bien en littérature que dans les arts plastiques ou en musique. Mozart, né à 12 kilomètres seulement de la frontière avec l'Empire ottoman, d'un opéra, l'Enlèvement au Sérail (1782), à un mouvement de sonate, appelé "Marche à la manière turque", symbolisera cet engouement orientalisant, précédé qu'il fût par Rameau et ses Indes Galantes ou par Gluck avec ses Pèlerins à la Mecque. Il sera suivi de Beethoven, de Rossini, avec son Ouverture du Turc en Italie, jusqu'au XIX siècle même, avec Verdi et son Othello, d'après l'ceuvre de Shakespeare, Othello ou le Maure de Venise. Les peintres de la Renaissance italienne mettent en scène, dans une Terre sainte totalement imaginaire, des Turcs fastueusement vêtus comme dans Les Noces de Cana de Véronèse, suivi là encore par nombre d'artistes, de Watteau à Delacroix. En Espagne, c'est Miguel de Cervantès qui, cinq années prisonnier des Turcs à Alger, profita de ce "séjour" involontaire pour étudier la société étrangère et étrange qui l'entourait et en tirer substance pour créer personnages et situations autour de son héros à la "Triste Figure", Don Quichotte de la Manche. L'auteur "véritable" en serait un Maure, Cid Hamet Ben Engeli, Cervantès nous présentant le manuscrit du Quichotte comme la traduction d'un texte arabe trouvé par hasard à Tolède et traduit par un Morisque, un de ces musulmans convertis de force au catholicisme...

Cette fascination pour les mondes turcs qui englobaient en fait de multiples cultures, s'est prolongée pendant plusieurs siècles, jusqu'à ce que les projets d'expansion européenne ainsi que la révolution kémaliste ne commencent à changer la donne. La conquête française de l'Algérie entraîne l'installation d'une nouvelle population en contact certes avec le vocabulaire berbère, arabe maghrébin (et même un peu espagnol), mais également avec le turc, langue de l'ancienne puissance occupante. Dès la conquête, ce sont les mots "dey", "bey" ou "janissaire" qui entrent dans notre vocabulaire. Comme il n'y eut pas de volonté colonisatrice de la part des Ottomans, peu de mots turcs pénétrèrent le vocabulaire courant maghrébin, si ce n'est dans celui de l'administration au sens large. De ces mots, les Français en retinrent un certain nombre, comme le chaouch, huissier rattaché à divers bureaux, le spahi, soldat faisant partie d'un corps de cavalerie constitué de Maghrébins, ou bien le bakchich promis à une renommée internationale. Jusqu'au XIX ${ }^{\mathrm{e}}$ siècle donc, ce seront moins de soixante-dix mots que la langue française empruntera au turc, l'ensemble de ce vocabulaire étant principalement ce qu'on peut appeler un vocabulaire lié au désir, au plaisir, bref non essentiel à l'évolution d'une civilisation, avant qu'il ne soit la conséquence de la colonisation européenne en Afrique du Nord, de la présence de ces gaouris arabisation populaire du turc gavur, "incroyant", et désignant encore aujourd'hui en Algérie les Français... 
Il faudra attendre la prise du pouvoir par Mustapha Kemal Atatürk, qui abolit le califat en 1924 et installe la nouvelle capitale de la Turquie indépendante à Ankara, pour que la langue turque subisse sa plus grande transformation depuis des siècles. Car non seulement l'alphabet arabe fut remplacé par un alphabet latin adapté, plus apte à "traduire" les sons du turc, mais encore le vocabulaire fut plus ou moins autoritairement renouvelé. Il y eut à la fois un retour à des formes plus spécifiquement "turques" et l'emprunt massif de mots étrangers, surtout français (pour des raisons essentiellement phonétiques, les sons de cette langue étant plus proches du turc que ceux de l'anglais, mais également historiques, les élites de la Turquie ottomane encore en place, étant le plus souvent francophones), emprunts très rapidement transformés, "turcisés" pour désigner tous les nouveaux objets ou concepts de la "modernité occidentale" que recherchait Atatürk.

\section{Des mots migrants}

Avec l'immigration turque en Europe occidentale au $\mathrm{XX}^{\mathrm{e}}$ siècle, arrivent de nouveaux mots transcrits tels quels en français et concernant en général des préparations culinaires... Il y avait bien eu, auparavant, la découverte de la bergamote, du loukoum ou du caviar, toutes choses délicieuses, mais réservées à une certaine élite. Avec l'installation de Turcs venus bien souvent des plateaux pauvres anatoliens, ce sont des préparations plus simples, plus consistantes, plus rapides qui vont s'imposer en Europe, et en France en particulier, où la vie sociale rend de plus en plus difficile la préparation longue des repas traditionnels. Ainsi, on pourra facilement et rapidement se restaurer chez "le Turc" de son quartier en commandant un chawarma, un döner-kebab, quelques kefta, avant de terminer par une pâtisserie au miel comme la baklawa.

Nul doute que cette aventure n'est pas terminée, les hommes ne cessant jamais, pour une raison ou une autre, par plaisir ou par nécessité, de voyager, mais également parce que les nouveaux moyens de communication virtuels amènent une circulation toujours plus importante des mots à la surface du globe.

C'est à une fécondation mutuelle que l'on assiste, à laquelle on participe. Contrairement à nombre d'idées reçues, l'enrichissement d'un vocabulaire est toujours le signe de découvertes croisées, d'une reconnaissance de l'existence de l'autre. Et les milliers de mots français qui ont enrichi le lexique turc contemporain en sont une des meilleures preuves.

\section{Notes}

1. Auteur du Dictionnaire étymologique des mots français venant de l'arabe, du turc et du persan, Paris, L'Harmattan, 2007. 